\title{
Prenatal Diagnosis of Fetus in Fetu with a Well Formed Skull: A Rare Case Report
}

\author{
Kishor Taori, Suresh Dhakate, Ramesh Parate, Jawhar Rathod, Amit Disawal, \\ Anand Hatgaonkar, Rahul Jain, Akshat Kasat, Dinesh Kumar \\ Government Medical College, Nagpur, India \\ Email: $\underline{\text { rahulsgr84@gmail.com }}$
}

Received 16 June 2014; revised 15 July 2014; accepted 8 August 2014

Copyright (C) 2014 by authors and Scientific Research Publishing Inc.

This work is licensed under the Creative Commons Attribution International License (CC BY). http://creativecommons.org/licenses/by/4.0/

c) (i) Open Access

\begin{abstract}
Fetus in fetu is an extremely rare condition embryologically arising in monozygotic diamniotic twins with an incidence of 1:500,000 births. To the best of our knowledge, number of reported cases should not be more than 100 with majority of cases presenting in post natal life with only 5 cases detected prenatally. We are presenting a case diagnosed at 24 weeks of gestation on ultrasound with presence of well formed skull, facial skeleton and bony orbit.
\end{abstract}

\section{Keywords}

Fetus in Fetu, Prenatal Diagnosis

\section{Introduction}

Meckel coined the term fetus-in-fetu (FIF), defined as a parasitic twin, in the 18th century [1]. Fetus in fetu represents a malformed, monochorionic diamniotic parasitic twin included in a host twin. Most of the cases report the parasitic twin to be anencephalic and acardiac. The presence of rudimentary spinal architecture is used to differentiate a fetus-in-fetu from a teratoma, since teratoma are not supposed to develop through the primitive streak stage (12 - 15 days) [2] [3]. We present the findings in a case of FIF that was diagnosed on prenatal ultrasound with emphasis on its closest differential diagnosis of teratoma.

\section{Case Report}

A 600 gm of male baby was born of preterm vaginal delivery at 25 weeks of gestation with a poor APGAR score of 4 . The neonate was resuscitated and shifted to the neonatal intensive care unit. On clinical examination there was distension of abdomen noted. The neonate expired 2 hours post-birth. The mother G3P0A2L0 yr old Indian had presented to the obstetrician at around 24 weeks of gestation with complain of excessive abdominal

How to cite this paper: Taori, K., Dhakate, S., Parate, R., Rathod, J., Disawal, A., Hatgaonkar, A., Jain, R., Kasat, A. and Kumar, D. (2014) Prenatal Diagnosis of Fetus in Fetu with a Well Formed Skull: A Rare Case Report. Open Journal of Obstetrics and Gynecology, 4, 710-715. http://dx.doi.org/10.4236/ojog.2014.412099 
distension. There was no prior ultrasound examination performed. A prenatal ultrasound examination performed in our department revealed polyhydroaminos with an amniotic fluid index of 32. However the most striking abnormality detected was the presence of intrabdominal hyperechoic structures with strong post-acoustic shadowing in the umbilical region of the fetus with morphological features resembling a well formed skull, a vertebral axis and poorly formed limbs (Figure 1, Figure 2). On doppler study the mass was supplied by 2 vessels arising from the abdominal aorta of the fetus (Figure 3). On the basis of these ultrasound findings a pre-natal diagnosis of fetus in fetu was kept; presence of a vertebral column over-riding its closest differential of fetal teratoma. Fetal magnetic resonance examination was advised. The mother however underwent preterm labor the next day. Post-mortem ultrasound revealed the presence of well formed skull, cranio-vertebral junction, vertebral axis, orbit, poorly formed limbs and abdominal viscera which confirmed our antenatal findings and diagnosis of fetus-in fetu (Figure 4, Figure 5). Postmortem CT scan backed our USG findings (Figure 6, Figure 7). On pathological autopsy there was mass lesion of size $6.9 \times 5.5 \times 4.6 \mathrm{~cm}$ with lucent membranes noted in the peritoneal cavity, attached to the bowel loops with cord like vessels arising from abdominal aorta of the host. Dissection of mass revealed membrane covered dysmorphic fetus with skull, poorly formed limbs and integument. Further dissection showed bilateral paravertebral reddish purple solid organ like structures which on microscopic examination turned out to be hepatic and splenic tissue respectively. Microscopic examination of tissue also confirmed presence of bones, cartilage, and neural tissue within it.

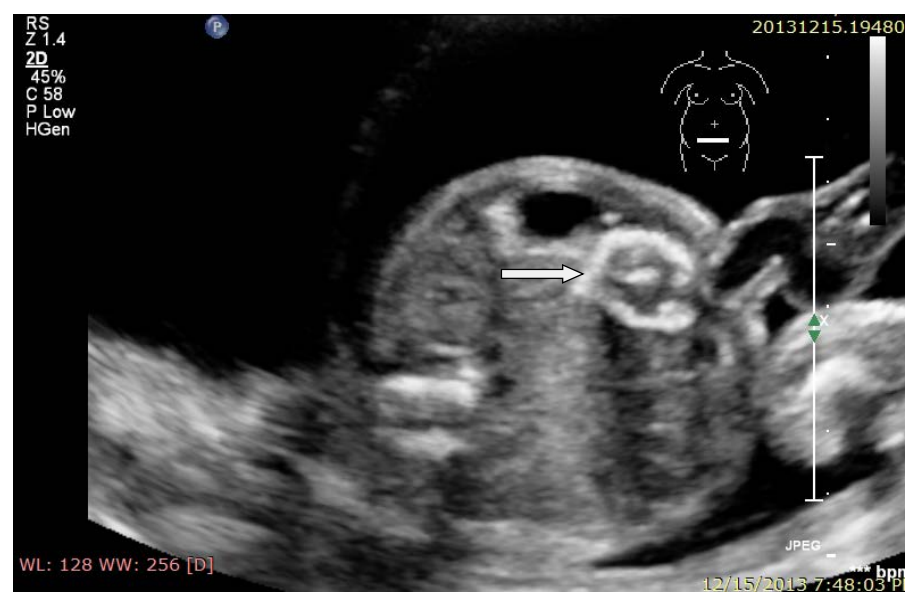

Figure 1. Prenatal ultrasound image showing a hyperechoic structure (arrow) with strong post acoustic shadowing morphologically resembling the fetal skull within the abdomen of the host twin.

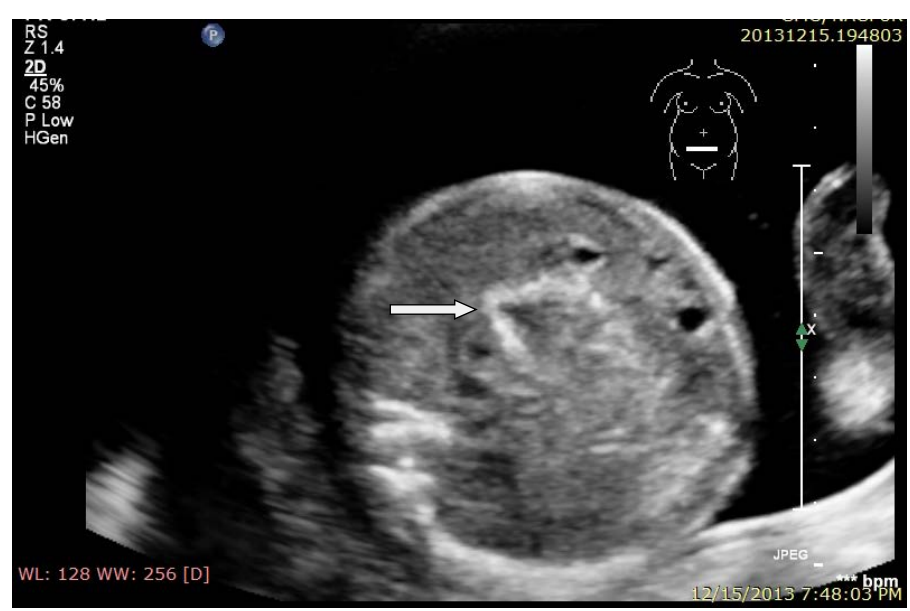

Figure 2. Prenatal ultrasound image showing hyperechoic curvilinear shadow (arrow) in continuity with the fetal skull (in above image) resembling the fetal spine. 


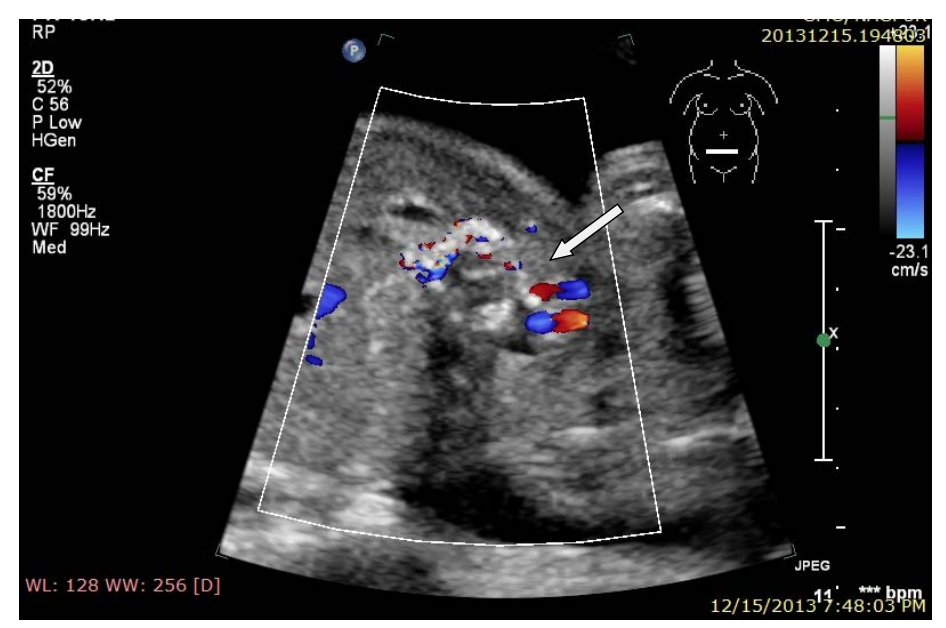

Figure 3. Prenatal ultrasound image showing vascular supply of the parasite twin from abdominal aorta of its host twin (arrow).

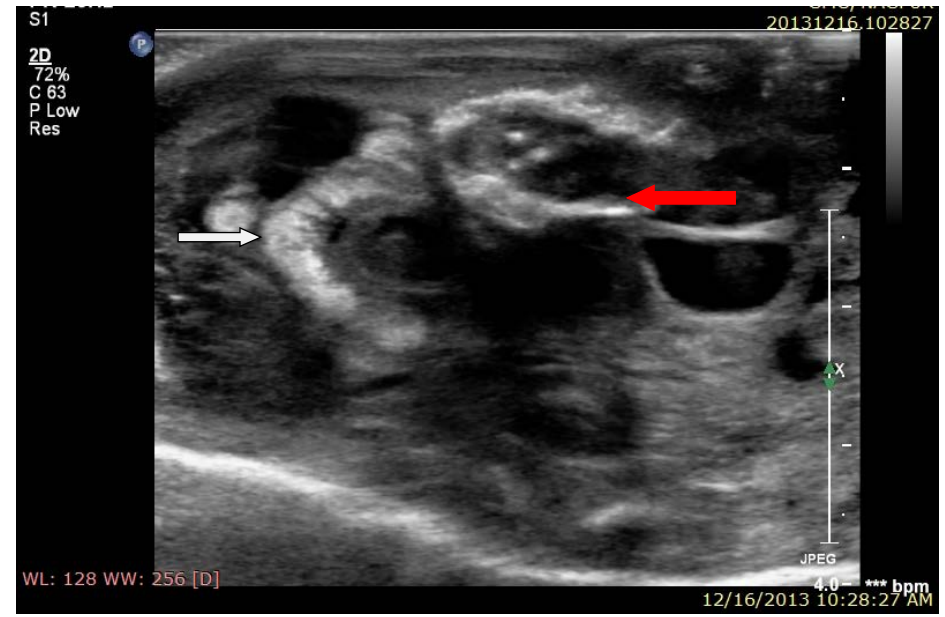

Figure 4. Postmortem ultrasound image well demonstrated the vertebral column (white arrow) and the skull (red arrow) of the parasitic twin within the abdominal cavity of the host sibling.

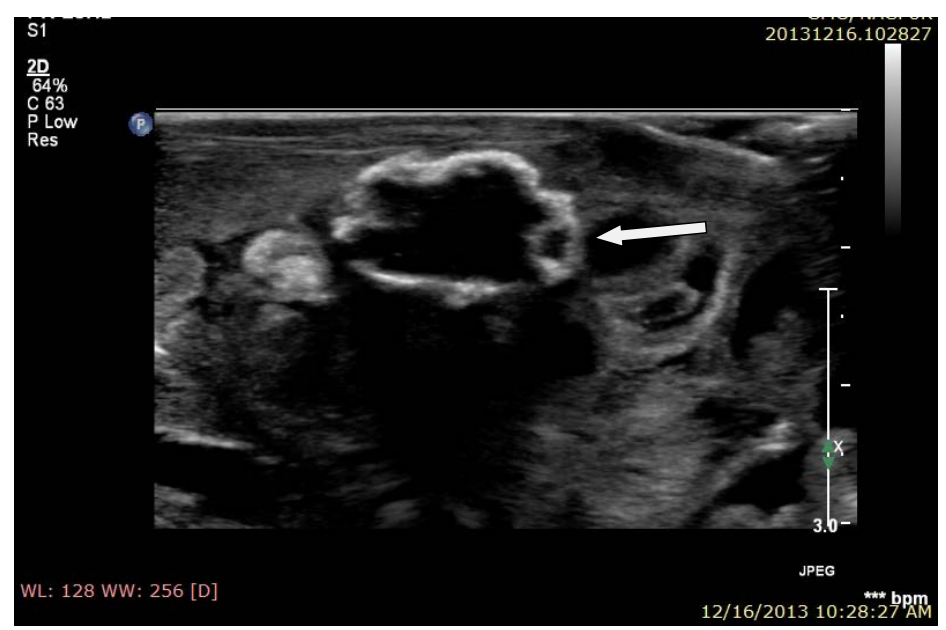

Figure 5. Postmortem ultrasound image well demonstrated the orbital shoket in skull of the parasitic twin (arrow). 


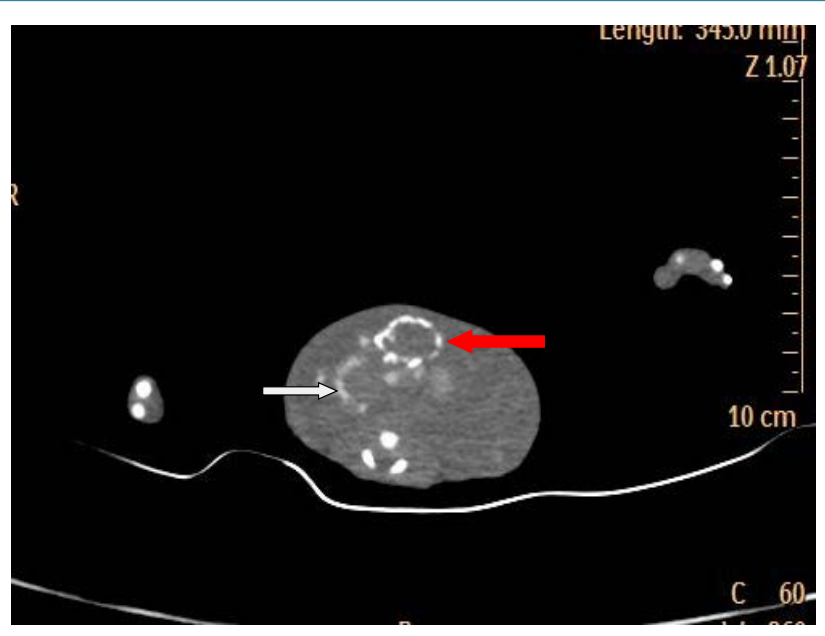

Figure 6. Postmortem CT scan image showing the vertebral column (white arrow) and the skull (red arrow) of the parasitic twin within the abdominal cavity of the host sibling.

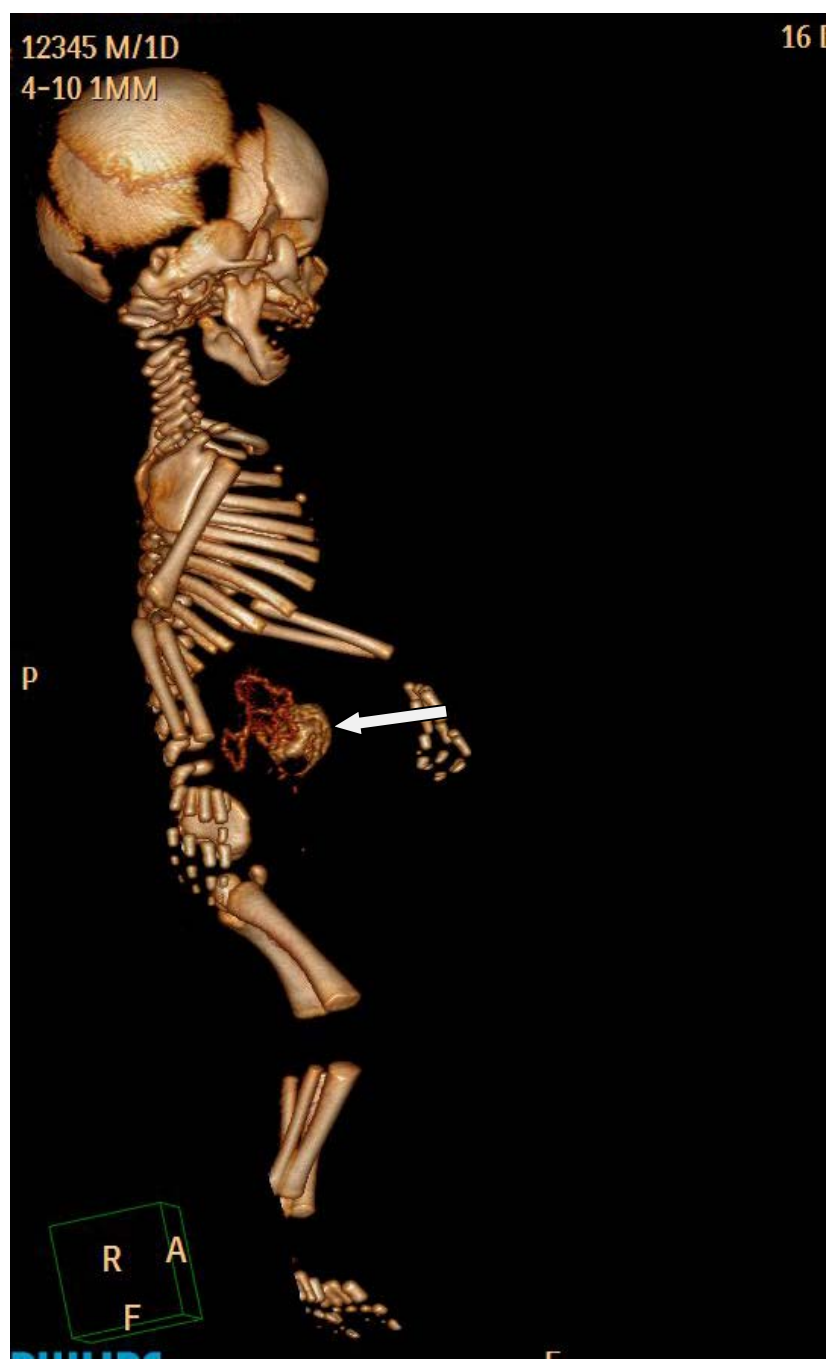

Figure 7. Post mortem volume rendered CT scan image showing the skull and spine of the parasite twin within the host (arrow). 


\section{Discussion}

Since Meckel's first report of a parasitic twin within its sibling there have been approximately 90 further reports of FIF in the medical literature [1]. Very few cases have been diagnosed prenatally using sonogram with the current literature suggesting about five cases thus discovered. [4] The condition is being detected most often in infants; however age of presentation varies from ante natal period upto as old as 47 years [5]. 89\% of the cases are discovered before the age of 18 months [6]. There are reports in which this anomaly remained asymptomatic until late age despite its prevalence in infants. In $80 \%$ the case mass is retroperitoneal [4]. Uncommon sites are oral cavity, sacrococcygeal region, scrotum, cranium, GIT, vessels, lungs, adrenal glands, spleen, lymph nodes and genitourinary system of the host twin [4].

The basic pathology is abnormal embryogenesis of a monozygotic diamniotic monochorinoic twin resulting from unequal division of the inner cell mass of the blastocyst leading to the parasitic twin developing within the body, usually the upper retro-peritoneum of its sibling [7]. Blood supply of the parasite twin is usually from the vitelline circulation of the host twin. Willis in 1935 distinguished it from a teratoma on the basis of presence of axial skeleton with limbs and organs arranged about this axis. Gonzalez-Crussi defined FIF as, "any structure in which the fetal form is in a very high development of organogenesis" and linked it "to the presence of a vertebral axis". In A recent review of all reported cases of FIF concluded that $91 \%$ of cases had a vertebral column, 82.5\% had limbs, 55.8\% had a central nervous system, $45 \%$ had a gastrointestinal tract and $40 \%$ had vessels. After the retro peritoneum other locations include the cranial \& oral cavity, pelvis \& sacro-coccegeal region [8]. In addition, the degrees of maturity exhibited by the individual features should be equal. The extent of development is variable in all cases and appears to rely on the degrees of vascular supply from the host as there has only been one case containing a functioning heart and no cases with a self supporting circulatory system [9]. It remains unclear what triggers the actual arrest in growth and further differentiation; some theories focus on host factors or nutrient supply being size limitations. Some believe the parasitic twin will continue to grow if enough vascularization is present [10] [11].

The FIF are usually anencephalic, with the vertebrae and limb-buds (long bones and bones of hands/feet can also present), and acardiac, rarely heart being found [4] [9] [12] [13]. (In our case, however the skull was well developed.) The parasite twin is enclosed within a fluid filled membrane resembling the amniotic membrane within the host twin. Usual clinical presentation is during infancy with symptoms due to compression of adjacent structures, however presentation during adulthood is also known. Diffuse calcifications in the abdomen on ultrasound offer differential diagnoses of FIF, teratoma and meconium pseudo cyst [14]. Radiologically the calcification is organized in FIF and resembles bones. Presence of pneumoperitoneum and ascites suggest the diagnosis of meconium pseudo cyst and peritonitis [15].

The treatment of choice for both fetus in fetu and teratoma is surgical resection. However, teratoma should be resected earlier because of their malignant potential, whereas the resection of fetus in fetu can be delayed until the infant is ready for surgery [5] [16]. CT scan usually helps confirm the diagnosis and in pre-operative assessment. The pathologic diagnosis is confirmed by the presence of a vertebral column, well-differentiated organs, and limb buds. Other criteria in the diagnosis of FIF include the presence of a capsule or fetal membranous covering, vascular connections, skin differentiation, and an umbilical cord with two vessels [4]. Presence of immature elements or poor organization of tissues suggesting poor organogenesis, raise the possibility of a teratoma with malignant potential, whereby clinical, radiological \& bio-chemical follow up (beta-HCG and alphafetoprotein) is warranted [17]. Incomplete resection of the surrounding membrane in fetus in fetu may give rise to malignancy.

In our case, the diagnosis of fetus in fetu was confirmed collaborating radiological findings of antenatal \& post-mortem ultrasound, CT and pathological findings. Autopsy revealed a solid mass with immature upper extremities and spine inside a fluid-filled sac surrounded by a transparent membrane. The solid mass was connected to the membrane by a tiny stalk including vessels. Microscopic evaluation of the solid mass had the general tissue characteristics of fetus in fetu, and the chorionic villi were absent.

\section{Conclusion}

Fetus in fetu should be considered when a solid mass with bony structures within a fluid-filled sac is detected in a fetus on antenatal sonography. Prenatal diagnosis using sonography and color Doppler imaging is possible, especially if a vertebral column is visualized. 


\section{References}

[1] Lee, E. (1965) Fetus in Fetu. Archives of Disease in Childhood, 40, 689-693. http://dx.doi.org/10.1136/adc.40.214.689

[2] Willis, R.A. (1962) The Borderland of Embryology and Pathology. 2nd Edition, Botterworths, London, 442.

[3] Kajbafzadeh, A.M. and Baharnoori, M. (2004) Fetus in Fetu. Canadian Journal of Urology, 13, 3277-3278.

[4] Hoeffel, C., Khoang, Q., Tran, T. and Fornes, P. (2000) Fetus in Fetu: A Case Report and Literature Review. Pediatrics, 105, 1335-1344. http://dx.doi.org/10.1542/peds.105.6.1335

[5] Dagradi, A.D., Mangiate, G.L., Serio, G.F., Muajo, F.G. and Menestrina, F.V. (1992) Fetus in Fetu Removal in 47 Years Old Man. Surgery, 112, 598-602.

[6] Hing, A., Corteville, J., Fogia, R.P., Bliss Jr., D.P., Donis-Keller, H. and Dowton, S.B. (1993) Fetus in Fetu: Molecular Analysis of a Fetiform Mass. American Journal of Medical Genetics, 47, 333-341. http://dx.doi.org/10.1002/ajmg.1320470308

[7] Gurses, N. and Bernay, F. (1990) Twin Fetuses in Fetu and Review of the Literature. Zeitschrift fur kinderchirurgie, 45, 319-322.

[8] Gonzalez-Crussi, F. (1982) Extragonadal Teratomas (Atlas of Tumor Pathology). 2nd Edition, Armed Forces Institute of Pathology, Washington DC.

[9] de Lagausie, P., de Napoli-Cocci, S., Stempfle, N., Truong, Q.D., Vuillard, E., Ferkadji, L., et al. (1997) Highly Differentiated Teratoma and Fetus in Fetu: A Single Pathology? Journal of Pediatric Surgery, 32, 115-116. http://dx.doi.org/10.1016/S0022-3468(97)90112-3

[10] Knox, A.J. and Webb, A.J. (1975) The Clinical Features and Treatment of Fetus in Fetu: Two Case Reports and a Review of the Literature. Journal of Pediatric Surgery, 10, 483-489. http://dx.doi.org/10.1016/0022-3468(75)90188-8

[11] Kim, O.H. and Shinn, K.S. (1993) Postnatal Growth of Fetus in Fetu. Pediatric Radiology, 23, 411-412. http://dx.doi.org/10.1007/BF02011978

[12] Federici, S., Ceccarelli, P.L., Ferrari, M., Galli, G., Zanetti, G. and Domino, R. (1991) Fetus-in-Fetu: Report of Three Cases and Review of the Literature. Pediatric Surgery International, 6, 60-65. http://dx.doi.org/10.1007/BF00174889

[13] Eng, H.L., Chuang, J.H., Lee, T.Y. and Chen, W.J. (1989) Fetus in Fetu: A Case Report and Review of the Literature. Journal of Pediatric Surgery, 24, 296-299. http://dx.doi.org/10.1016/S0022-3468(89)80017-X

[14] Hing, A., Corteville, P., Ferrari, M., Galli, G., Zanetti, G. and Domini, R. (1993) Fetus in Fetu: Molecular Analysis of a Fetiform Mass. American Journal of Medical Genetics, 47, 333-341. http://dx.doi.org/10.1002/ajmg.1320470308

[15] Baldwin, V. (1991) Pathology of Multiple Pregnancy. In: The Textbook of Fetal and Prenatal Pathology, Blackwell Science, Boston, 409p.

[16] Mohta, A., Shrivasatava, U.K., Sodhi, P. and Upret, L. (2003) Fetus-in Fetu. Pediatric Surgery International, 19, 499500. http://dx.doi.org/10.1007/s00383-002-0943-8

[17] Alpers, C.E. and Harrison, M.R. (1985) Fetus in Fetu Associated with an Undescended Testis. Fetal \& Pediatric Pathology, 4, 37-46. http://dx.doi.org/10.3109/15513818509025901 
Scientific Research Publishing (SCIRP) is one of the largest Open Access journal publishers. It is currently publishing more than 200 open access, online, peer-reviewed journals covering a wide range of academic disciplines. SCIRP serves the worldwide academic communities and contributes to the progress and application of science with its publication.

Other selected journals from SCIRP are listed as below. Submit your manuscript to us via either submit@scirp.org or Online Submission Portal.
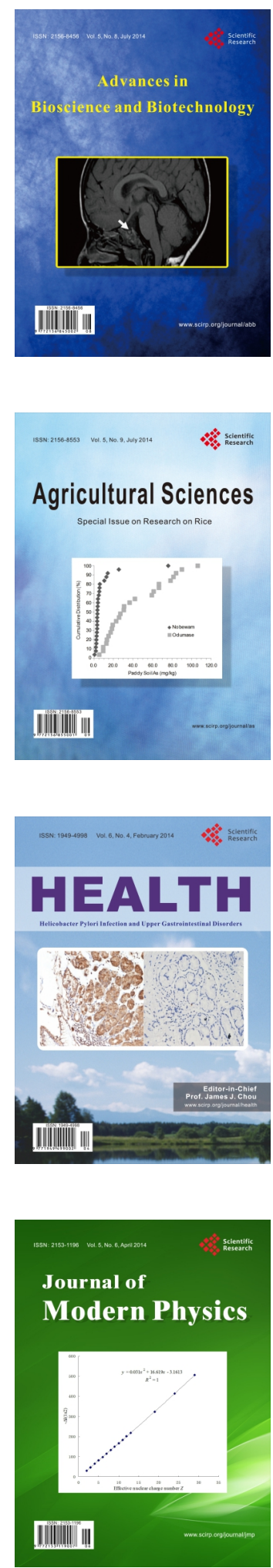
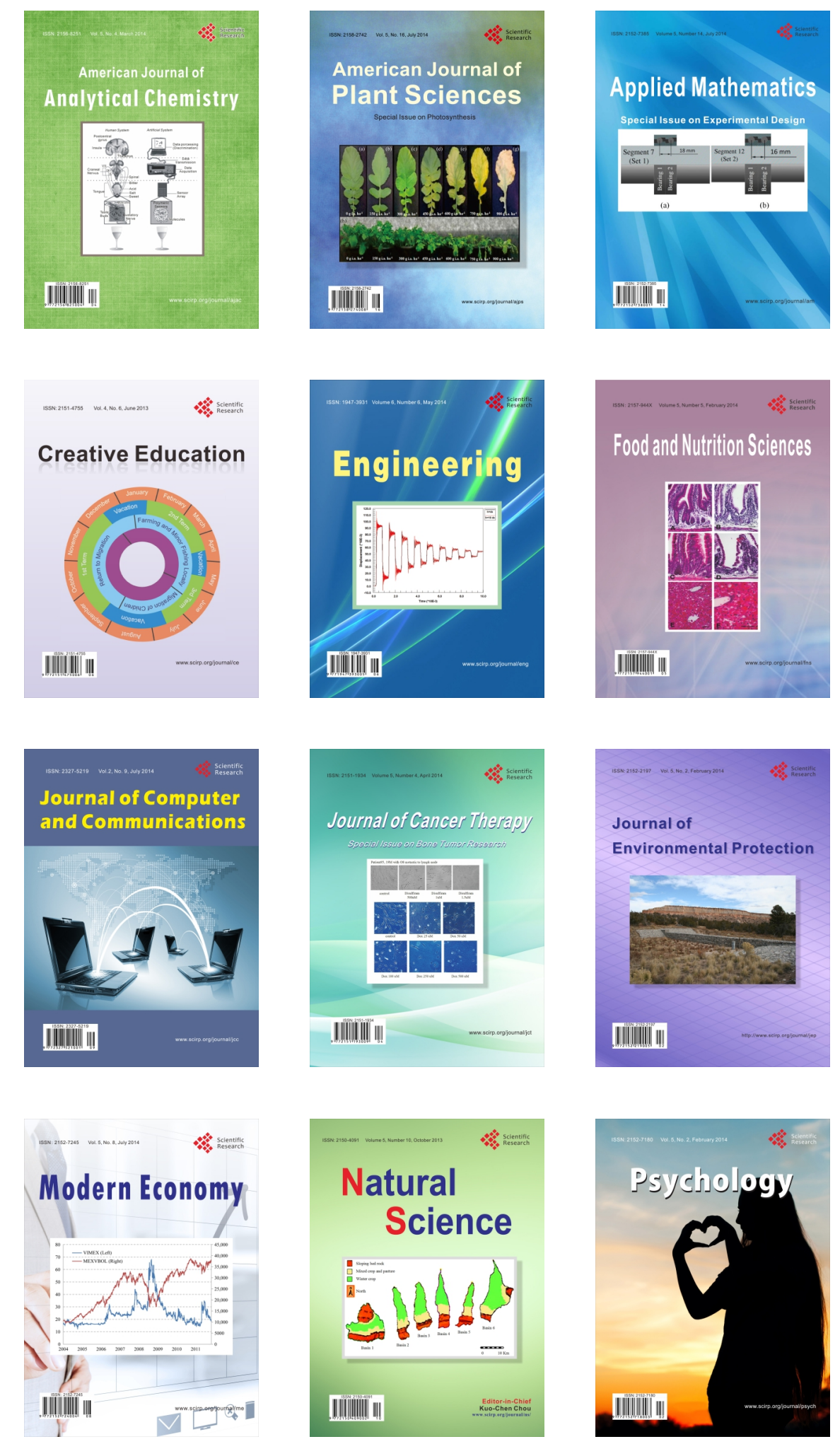